\title{
OS LIMITES DA LIBERDADE DE EXPRESSÃO: FAKE NEWS COMO AMEAÇA A DEMOCRACIA
}

\section{THE LIMITS OF FREEDOM OF EXPRESSION: FAKE NEWS HOW THREATENING A DEMOCRACY}

\author{
André Soares Oliveira \\ Patrícia Oliveira Gomes
}

\section{RESUMO}

A disseminação de notícias falsas corrói a democracia ao criar desinformação que bloqueia o debate. Esse artigo trata a relação entre a liberdade de expressão e a divulgação massiva de notícias falsas, avaliando os riscos à democracia, considerando estudos e as tendências políticas atuais. Utiliza-se o método indutivo e o procedimento bibliográfico e documental. Os desafios democráticos exigem enfrentar as questões contraditórias decorrentes de sociedades hiperconectadas que transformou os modos de vida e de construção dos debates políticos. A atuação do Tribunal Superior Eleitoral sugere ainda está muito aquém e também demarca os limites de atuação legal nesse contexto.

Palavras-chave: Fake news. Liberdade de expressão. Democracia.

\section{ABSTRACT}

The spread of fake news erodes democracy by creating disinformation that blocks debate. This article deals with the relationship between freedom of expression and the mass dissemination of fake news, assessing the risks to democracy, considering studies and current political trends. The inductive method and the bibliographic and documentary procedure are used. Democratic challenges require tackling the contradictory issues arising from hyperconnected societies that have transformed the way of life and the construction of political debates. The action of the Superior Electoral Court suggests is still far behind and demarcates the limits of legal action in this context.

Keywords: Fake news. Freedom of expression. Democracy. 


\section{INTRODUÇÃO}

0 ano de 2016 foi um marco para trazer a temática à tona, tendo em vista que dois eventos políticos de repercussão mundial foram marcados pela utilização das notícias falsas: as eleições presidenciais norte-americanas e o referendo que decidiu pela saída do Reino Unido da União Europeia (Brexit) ${ }^{1}$. Não por acaso, no mesmo o ano, o dicionário de Oxford definiu a "pós-verdade" como palavra do ano. 0 conceito é "relativo ou referente a circunstâncias nas quais os fatos objetivos são menos influentes na opinião pública do que as emoções e as crenças pessoais." (HANCOCK, 2016)

A noção de pós-verdade situa bem o problema das notícias falsas: não se trata apenas de exagerar ou ocultar questões, tampouco da emissão de opiniões ou interpretações, mas do discurso que trata como verdadeiros fatos inexistentes e que ganham adesão porque as pessoas querem acreditar que ele aconteceu.

É sabido que os boatos, as mentiras, a propagação de ideias absurdas e preconceituosas não são novidades na política, e sempre pautaram desde os conflitos locais até as disputas internacionais. Do ponto de vista jornalístico, a produção de factóides pela "imprensa marrom”, é algo com o que sempre se conviveu. Também não é novidade o enviesamento na abordagem da notícia ou mesmo erros na sua apuração por parte de muitos veículos jornalísticos tradicionais.

Apesar disso, é necessário reconhecer que o fenômeno das notícias falsas pós-2016 são a ponta de um iceberg de um processo complexo de desinformação e radicalização política em que as velhas ameaças à democracia ganham uma nova roupagem, dado o sistema tecnológico em que os novos mecanismos estão envolvidos.

É impossível pensar os desafios democráticos atuais sem enfrentar as questões contraditórias oferecidas pelo avanço tecnológico das sociedades hiperconectadas que transformou os modos de vida, de interação social e de construção dos debates políticos. Nesse sentido, esse artigo tem por objetivo tratar a relação entre direito à informação, liberdade de expressão e o problema da divulgação massiva de notícias falsas, por meio da internet, avaliando como essas oferecem riscos à 
democracia, considerando os estudos e as tendências políticas atuais. Será feita ainda uma breve análise sobre a atuação do Tribunal Superior Eleitoral nas eleições brasileiras de 2018 em relação às "fake news".

\section{OS DESAFIOS DAS NOTÍCIAS FALSAS PARA AS DEMOCRACIAS CONTEMPORÂNEAS}

A internet é um meio de informação e comunicação, e como tal, um espaço de ação política. De acordo com a Pesquisa Brasileira de Mídia - 2016 - Hábitos de consumo de Mídia, da Presidência da República, 89\% dos entrevistados entendem que é possível obter informações mais diversas na internet do que nos canais de TV aberta (MARTINS, 2017). Por outro lado, segundo pesquisa da BBC World Service, os brasileiros estão entre os mais preocupados com a nebulosa linha entre o que é real e falso na internet, sendo que $92 \%$ relatam alguma preocupação (CELLAN JONES, 2017).

Diante da disseminação da desinformação sobre os mais variados assuntos, emergem os questionamentos sobre como a internet pode ser um espaço livre para a comunicação, o que passa inclusive, pela compreensão dos usuários a seu respeito. Uma pesquisa divulgada pela Quartz identificou que, no Brasil, 55\% dos usuários concordam com a afirmação: “O facebook é a internet?” (SUMARES, 2017), o que demonstra um grave desconhecimento sobre a utilização da rede, logo, uma vulnerabilidade diante do seu potencial informativo.

A insegurança gerada pela desinformação constitui por si só uma ameaça à democracia e a pluralidade política. A situação se agrava no contexto mundial em que a reascensão de ideais ultraconservadores e segregacionistas vem ganhando ares de normalidade e aponta-se que a difusão de notícias falsas tem servido especialmente à sua propagação, embora sejam utilizadas por grupos de diferentes espectros políticos (CORSALETTE, 2018).

Wardle e Derkarshian (2017) apontam como a eleição dos EUA (2016), a decisão pelo Brexit (2016), a força da candidata de extrema direita Marie Le Pen na França (2017) e as eleições presidenciais no 
Quênia (2017) são eventos que alertam para o potencial poder das campanhas de desinformação, embora não existem dados empíricos capazes de mensurar a sua exata influência.

Os mesmos autores, inspirados em James Carey, autor da obra "Communication as Culture: Essays on Media and Society" (1989) trazem à tona a dimensão ritualística do processo de produção e consumo de informações. Ler uma notícia não se trata apenas um processo de informação-transmissão, mas está relacionada com retratar e confirmar uma determinada visão de mundo, trazendo em si também um aspecto dramático. 0 conteúdo problemático mais bem sucedido é o que joga com desprezo, raiva ou medo. (WARDLE E DERKARSHIAN, 2017)

Diante desse contexto, pontuamos a seguir alguns aspectos que entendemos relevantes para compreender a problemática das notícias falsas e os aspectos em que elas constituem um desafio para democracia.

\section{a) Uma terminologia adequada}

Ao passo em que se tornou uma pauta pública, a terminologia "fake news" passou a ser utilizada para desqualificar informações simplesmente desagradáveis ou que apuradas com maior tempo e cuidado, revelaramse não verdadeiras, o que sempre fez parte da dinâmica do jornalismo e da liberdade de expressão.

Tal imprecisão terminológica gera uma descrença generalizada nas fontes de informações. Pior, o termo se transformou em arma discursiva para negar medidas de governos autoritários, somadas às suas investidas contra a liberdade de imprensa. Erlanger (2017), explicita como a retórica do presidente norte-americano Donald Trump, que comumente estigmatiza as mídias tradicionais como produtoras de "fake news', tem se estendido a outros dirigentes autoritários, populistas e demais líderes políticos, para simplesmente rejeitar a crítica das mídias e análise de seus governos.

Como exemplos, temos a reação do presidente sírio Bashar al Asad à publicação do relatório da Anistia Internacional sobre morte em prisões naquele país, dizendo que "estamos vivendo em uma época de notícias 
falsas"; a resposta do governo de Mianmar à constatação de observadores internacionais das Nações Unidas de que o Exército nacional promovia um genocídio contra a minoria muçulmana rohingya, informando que “isso não acontecia e que eram notícias falsas". A mesma justificativa já foi dada pelo presidente venezuelano Nicolás Maduro e pelos governos russo e chinês sobre as críticas que recebem. (ERLANGER, 2017)

Não é possível categorizar toda sorte de informação não "plenamente" correta, como uma notícia falsa. A partir de um diagnóstico geral de como a expressão "fake news" é utilizada para fenômenos diferentes, que incluem até mesmo sátiras ou propagandas, bem como do problema da apropriação do termo acima exposto, Wardle e Derakhshan $(2017)^{2}$ propõem uma nova terminologia para o que denominam de fenômeno de transtorno de informação (information disorder).

Os autores identificam três noções comumente envolvidas no discurso das notícias falsas: a) informação errada (mis-information), quando informações falsas são compartilhadas sem intenção de gerar danos; b) desinformação (dis-information), quando informações falsas são compartilhadas com a intenção de causar danos; c) informação má (malinformation), quando informações genuínas são compartilhadas para causar danos a pessoa, organização ou país. Destacam que é importante tanto distinguir notícias verdadeiras das falsas, quanto as que são criadas, produzidas e distribuídas com a intenção de prejudicar, das que não são ${ }^{3}$.

A noção de desinformação coaduna com a terminologia defendida pelo professor e jornalista Carlos Eduardo Lins e Silva, que substitui a expressão "notícias falsas" por notícias fraudulentas, tendo em vista que estas são criadas com a intenção de enganar as pessoas, como destaca Bucci (2018).

Outro aspecto analítico importante segundo Wardle e Derakhshan (2017) é destacar que existem três fases do transtorno da informação: a criação, a produção e a distribuição; assim como existem três elementos envolvidos: o agente, a mensagem e o intérprete. É importante então compreender, quem são os agentes que criam, produzem e distribuem as notícias falsas e quais são suas intenções, assim como qual o formato da mensagem, em que meio ela é divulgada, como ela é interpretada e qual a atitude tomada por quem a recebe. Comumente não são os mesmos 
agentes que criam, produzem e distribuem as notícias, assim como são diferentes as suas motivações, que podem ser financeiras, políticas, sociais e psicológicas.

Nesse ponto, destacam que comumente se considera a desinformação pela produção de textos escritos, sendo necessário voltar a atenção ao conteúdo visual - memes, imagens, vídeos, gráficos - cuja autenticidade muitas vezes é mais difícil de contestar e cujo impacto pode ser potencialmente maior, pela sua maior capilaridade de divulgação (WARDLE e DERAKHSHAN, 2017).

\section{b) $\mathbf{O}$ problema da fonte da informação}

O problema da fonte é central no processo de desinformação. Inicialmente, temos a questão de que qualquer pessoa, em qualquer lugar do mundo ${ }^{4}$, pode criar um site pseudojornalístico que difunde notícias falsas e que, conforme visto acima, pode ter a mesma repercussão de uma mídia tradicional. Na desinformação, existe uma preocupação maior com a história do que com a fonte, tendo em vista que os meios passam a ter a mesma credibilidade (WARDLE E DERKASHIAN, 2017).

Além disso, temos a desinformação repassada por aplicativos de conversa privada como whatsapp, em que sequer é necessária uma notícia propriamente dita, mas basta uma mensagem de texto ou imagem cuja autoria pode ser atribuída a qualquer pessoa ou a ninguém. Nesse caso, o problema da fonte se agrava, pois ela é o próprio remetente da mensagem, pessoa da sua rede de confiança e/ou convivência, o que torna a contestação à informação, no mínimo, mais desconfortável.

O conflito de fontes de informação legítimas ou não também está baseado na promoção da desmoralização geral dos veículos jornalísticos que faz com que se busque como única fonte legítima o grupo ou liderança política seguida. A lógica elimina os intermediários no processo de comunicação, evidenciando a relação de autoritarismo construída.

Aqui vale destacar a diferença no envolvimento de atores oficiais ou não oficiais na desinformação, considerando-se que a aquela produzida pelos primeiros normalmente tem maior sofisticação, financiamento e 
impacto. Como exemplos existem as táticas do governo russo em dar suporte para a criação da maior quantidade de informações contraditórias por atores governamentais ou não governamentais controlados pelo governo, a fim de convencer o público de que há tantas versões, que não é possível reconhecer a verdadeira. (WARDLE e DERAKHSHAN 2017)

\section{c) Direcionamento, algorítmos e o debate na esfera pública}

A política é o espaço de encontro das diferenças, da pluralidade, defende Hanna Arendt (CLETO, 2016). Todavia, a tendência das relações políticas na internet segue o caminho contrário. Cada vez mais o acesso do usuário à internet se dá pela regulação algorítmica da atenção, baseada na proximidade e na crença. Ou seja, os circuitos acessíveis nas redes passam por filtros de localização física e de afinidade de interesses.

Tal sistema favorece a formação de bolhas sociais, em que todos parecem concordar ou agir de forma semelhante. É como se cada pessoa vivesse um espelho de suas próprias conviç̧ões e práticas, acreditando ser aquilo o retrato da pluralidade social.

As bolhas facilitam também o direcionamento de (des)informações e ajudam a radicalizar os posicionamentos políticos pela ausência do contraponto, de outra visão, o que muitas vezes é buscado por nós mesmos, que não suportamos a avalanche do "contrário" em nossas redes sociais (BRANCO S., 2017). A situação é agravada ainda pela atuação organizada dos trolls, pessoas que utilizam de perfis virtuais e atuam de forma desestabilizar uma discussão através das ofensas sistemáticas e pessoais, amplificam a desinformação, através do silenciamento dos antagonistas. (WARDLE E DERAKHSHAN, 2017)

Um aspecto relevante é também a utilização de robôs, os bots. As contas automatizadas tem capacidade de driblar os algoritmos para ganhar visibilidade e adesão de perfis humanos que compartilharão suas ideias. Muitos bots são criados para ampliar o alcance da desinformação, explorar vulnerabilidades que decorrem dos vieses cognitivos e sociais, além de criar a ilusão que inúmeras pessoas endossam aquela informação. 
Wardle e Derakhshan (2017) apontam ainda, que segundo Ferrara (2016), muitos bots engajados nas eleições de Trump, fizeram o mesmo na campanha anti-Macron, nas eleições presidenciais francesas, embora tenham mantido pouca atividade entre um evento e outro, o que indicaria a existência de um mercado negro de bots.

O chamado viés de confirmação, ou seja, a nossa tendência a concordar com a informação ou leitura da realidade que mais se aproxime do que acreditamos, sempre existente, tende a ser intensificado nesse processo comunicacional, o que favorece a desinformação. (CORSALETTE, 2017).

A atuação da empresa Cambridge Analytica nas campanhas do então candidato a presidente Donald Trump e pelo "sim" ao Brexit levantou a questão do direcionamento. A partir da captação de dados de cerca de 87 milhões de pessoas, a empresa utilizou-se de métodos de psicometria para traçar um perfil de personalidade do eleitor e a identificação da probabilidade de sua reação diante de determinados conteúdos, bem como, o momento certo de expô-los a eles.

O próprio site da empresa indica o paradigma: "Dados movem tudo o que fazemos. Cambridge Analytica usa os dados para mudar o comportamento do público". A empresa se divide nos ramos comercial e político. Na página da CA Political são explicitada os seus métodos de ação: "combinação de análise de dados preditivos, ciência comportamental e tecnologia de publicidade inovadora.", de forma a segmentar o público a partir da análise comportamental, identificando para quem e o que tipo de campanha pode ser mais persuasiva. ${ }^{5}$

Trata-se de uma tendência que segue a lógica contemporânea das diversas relações humanas, em termos de individualização e fragmentação. 0 direcionamento de conteúdos exclui a apreciação da informação da esfera pública, e dificulta o combate a desinformação pela própria lógica fragmentada. Se, por exemplo, o "Jornal Nacional", com sua conhecida influência na formação da opinião pública, lança um editorial, está sujeito a análise crítica de um conjunto plural de sujeitos. Nesse paradigma, não.

Pasquale (2017) explica que decisões sobre as pautas jornalísticas, que antes eram tomadas por funcionários, caso a caso, hoje são questões algorítmicas e automáticas, o que impacta a agenda pública e 
a democracia. Aponta ainda necessidade de criação de mecanismos de responsabilização dos agentes intermediários de divulgação das notícias falsas, tais como Google e Facebook, tendo em vista que a sua facilidade de proliferação neles está relacionada aos critérios de programação:

As escolhas básicas de programação e design dos sites como Facebook ou Google ensejam que os conteúdos digitais compartilhados tenham se mantido com características e temáticas similares há anos (CHAYKA, 2016). Assim, uma notícia falsa do "Denver Guardian" [site de notícias falsas] pode, a primeira vista, passar tanta credibilidade quanto uma matéria premiada com o Prêmio Pulitzer do New York Times (LUBBERS, 2016). Sucintamente, é possível afirmar que o Facebook lucra com a proliferação de notícias falsas. Quanto mais notícias compartilhadas (independentemente de sua veracidade) mais receita os anúncios geram para a empresa (MOLINA, 2016). De forma mais perturbadora, agora sabemos que o Facebook ajudou diretamente à campanha Trump no desestímulo a participação eleitoral dos afroamericanos (WINSTON, 2016).

O Google, por sua vez, enfrentou escândalos ligados a questões raciais (NOBLE, 2018). A ferramenta de autopreenchimento de termos de busca, por exemplo, incorporou por diversas vezes estereótipos racistas e sexistas (CADWALLADR, 2016). Pesquisas de imagens do buscador também geraram resultados preconceituosos, absurdamente identificando algumas fotos de pessoas negras como "gorilas" (GUARINO, 2016; BARR, 2015)." (PASQUALE, 2017, 20)

Assim, entende que se as plataformas tivessem agendas ideológicas publicamente reconhecidas, os usuários poderiam receber com maior ceticismo os conteúdos ofertados por elas. Com efeito, a noção romântica de liberdade da internet esbarra no fato de que a internet é controlada globalmente pelas corporações Google, Facebook, Amazon, Apple, Tencent, AliBaba, com seus interesses mercadológicos próprios, o que compromete a sua saúde enquanto mecanismo democrático (MOZILLA, 2018).

A preocupação aumenta diante da compreensão da funcionalidade dos algoritmos e das estruturas dos sites por grupos extremistas que os utilizam para difundir ideias "que estão à margem da respeitabilidade política e validade científica", dentre as quais, as que negam as mudanças climáticas, misóginas, etnonacionalistas, antisemitas e terroristas. (PASQUALE, 2017, p.20) 
Toda essa nova realidade só é possível graças a enorme quantidade de dados pessoais - big data - disponibilizados por nós nas redes e a capacidade de sua análise e intepretação por inteligência artificial. Temos um novo instrumento de poder e de manipulação do comportamento, a partir dos mecanismos tecnológicos.

Para ilustrar o cenário, vale mencionar a pesquisa da Universidade de Cambridge e da Universidade de Stanford com mais de 80 mil voluntários que preencheram um teste de personalidade com mais de 100 itens, por meio do aplicativo "mypersonality", ao passo em que cederam o acesso a suas "curtidas" no Facebook.

O software, a partir da interpretação de uma determinada quantidade de "curtidas", foi capaz de prever melhor a personalidade do usuário do que as pessoas que convivem com ele. 0 pressuposto é que computadores conseguem avaliar melhor os aspectos da personalidade humana do que os próprios humanos, cujo cérebro tende superdimensionar ou ocultar questões ${ }^{6}$ (DAILYMAIL, 2015).

\section{LIBERDADE DE EXPRESSÃO: ASPECTOS DE DIREITO INTERNACIONAL E TRATAMENTO CONSTITUCIONAL}

A liberdade de expressão é essencial entre os direitos fundamentais que se gozam numa sociedade liberal. É por meio da liberdade de expressão que mesmo o Estado permite que suas leis sejam publicamente contestadas e, tão logo, alteradas, de modo que as restrições que impõe a outros direitos sejam adimplidas pelos cidadãos. Em outras palavras, é no exercício da liberdade de expressão que o Estado consegue legitimar-se e o próprio compromisso com uma democracia liberal implica em respeito pela liberdade de expressão (BARENDT et al., 2014).

A garantia da liberdade de expressão aparece, pela primeira vez, de modo tímido, no item $9^{7}$ da Declaração de Direitos inglesa, de 1688, quando se assegura o que hoje se conhece como imunidade material dos parlamentares no que toca a opiniões e votos proferidos no Parlamento. A Declaração de Direitos do bom povo da Virgínia, em 1776, dentro do contexto da Revolução Americana, traz apenas um item ${ }^{8}$ sobre a liberdade 
de imprensa. A Declaração de Direitos do Homem e do Cidadão, de 1789, também traz uma menção sobre a liberdade de expressão ${ }^{9}$.

Hoje, existe uma mudança no perfil do exercício da comunicação e tão logo da liberdade de expressão por meio da rede mundial de computadores, que é vista como uma terra sem lei, propícia tanto para a disseminação de informações que fazem germinar o debate quanto de informações que, ao contrário, envenanam o debate com notícias falsas e disseminam a desinformação.

O próximo item buscará uma reflexão breve sobre o status da liberdade de expressão e direito à informação no direito internacional, seguida de uma reflexão no âmbito constitucional.

\section{a) No direito internacional}

No âmbito do direito internacional, a liberdade de expressão está prevista no artigo $19^{10}$ da Declaração Universal dos Direitos Humanos de 1948 e no artigo $19^{11}$ do Pacto de Direito Civis e Políticos, internalizado no Brasil por meio do Decreto no 592/1992. No âmbito regional, a Convenção Europeia dos Direitos Humanos, adotada pelos Estados-Membros do Conselho da Europa em 1950, trata da liberdade de expressão no seu artigo $10^{12}$ e, no âmbito regional americano, o Pacto de São José da Costa Rica - Convenção Americana de Direitos Humanos - de 1969, consagra o mencionado direito no artigo $13^{13}$.

Das previsões legais contidas no Pacto e nas Convenções regionais de direitos humanos, pode-se ver uma preocupação comum de que o exercício da liberdade de expressão, como qualquer outro direito, não deve ser invocado como um direito absoluto, mas encontra-se limitado pelo exercício de outros direitos. O Pacto menciona como limite 'deveres e responsabilidades especiais', além da possibilidade de leis que o restrinjam tendo em vista a manutenção da ordem pública. $\mathrm{Na}$ mesma esteira, a Convenção europeia chama a liberdade de expressão à responsabilidade tendo em vista deveres e responsabilidades necessários para, entre outros valores, a manutenção da ordem em uma sociedade democrática. A Convenção americana também está no mesmo sentido. 
Com o advento das notícias falsas, o debate internacional sobre a liberdade de expressão ganhou um novo contorno. 0 tema adentra fortemente a agenda de debate internacional das organizações internacionais de direitos humanos ao ponto que, em 03 de março de 2017, o Relator Especial das Nações Unidas para Liberdade de Expressão, o Representante de Liberdade de Imprensa da Organização para a Segurança e Cooperação na Europa, o Relator Especial sobre Liberdade de Expressão da Organização dos Estados Americanos e o Relator Especial sobre Liberdade de Expressão e Acesso à Informação da Comissão Africana de Direitos Humanos e dos Povos publicaram uma Declaração Conjunta sobre Liberdade de Expressão, Notícias Falsas, Desinformação e Propaganda (UNITED NATIONS, 2017).

A Declaração Conjunta se inicia traçando um panomara de deseminação de desinformação tanto pelos Estados quanto por agentes não-estatais cujo objetivo é desinformar toda uma população, violando reputações, incitando o ódio e o preconceito e mesmo desacreditando os veículos de comunicação.

Porém, é interessante notar a discussão estampada na Declaração Conjunta quando ela afirma que a proteção da liberdade de expressão não está limitada apenas a informações 'corretas', mas abrange também aquelas que possam chocar ou mesmo ofender, e que restrições à liberdade de expressão a fim de combater a desinformação também seriam restrições injustificadas à liberdade de expressão.

As restrições à liberdade de expressão apenas são possíveis se, de acordo com a Declaração Conjunta, elas procuram proteger um fim legítimo de acordo com o direito internacional e sejam necessárias e proporcionais ao objetivo almejado. Nesse sentido, a leis gerais que impeçam a divulgação de notícias porque baseadas em ideias vagas ou mesmo ambíguas não estão de acordo com o direito internacional e ferem a liberdade de expressão.

Nesse sentido, a Declaração Conjunta entende que o melhor caminho de combater a disseminação da desinformação é, na verdade, aumentar a disseminação da informação, impondo aos Estados a obrigação de promover a maior diversidade possível de meios de comunicação onde a população possa se informar. Além disso, a Declaração Conjunta ressalta 
a importância de um serviço de mídia público, forte e independente, que sirva aos mais variados interesses e mantenha um alto padrão de jornalismo.

Outra preocupação da Declaração Conjunta é com os intermediários, ou seja, serviços tais como as redes sociais, que devem adotar políticas claras e pré-determinadas no exercício de sua função de deletar informações falsas de suas bases, impedindo sua disseminação, mas tendo como base critérios claros e objetivos, independetemente das ideologias políticas representadas.

\section{b) No plano constitucional: a liberdade de expressão}

De acordo com José Afonso da Silva, a liberdade de comunicação compreende um "conjunto de direitos, formas, processos e veículos, que possibilitam a coordenação desembaraçada da criação, expressão e difusão do pensamento e da informação" (SILVA, 2017, p.245). A liberdade de comunicação engloba, na visão do autor, a liberdade de expressão, uma vez que inclui tanto aspectos relacionados ao conteúdo quanto ao meio de sua difusão. Sendo assim, esses direitos estariam nos incisos IV ${ }^{14}, \mathrm{~V}^{15}$, $\mathrm{IX}^{16}{ }^{16}$ XII $^{17}$ e XIV ${ }^{18}$, todos do art.5o da Constituição Federal. Silva (2017) destrincha a liberdade de comunicação em liberdade de manifestação do pensamento, liberdade de informação em geral e liberdade de informação jornalística.

No âmbito da liberdade de pensamento, a mesma está amparada no inciso IV do art. $5^{\mathrm{o}}$ e no art. $220^{19}, \S \S 1^{\mathrm{o} 20}$ e $2^{\mathrm{o} 21}$, da Constituição Federal. Essa liberdade realiza-se na comunicação entre presentes e também entre ausentes, sejam eles determinados ou indeterminados, como é o caso da internet. Entre os argumentos que justificam a proteção da liberdade de expressão deve-se ter em mente a indispensabilidade do debate como fundamento da própria democracia e que, para que o debate seja possível, é imperioso que os discursos sejam protegidos de arbitrariedades do poder, tais como a censura (BRANCO, 2018).

É interessante notar que "a liberdade de manifestação do pensamento tem seu ônus [...] assumir claramente a autoria do produto 
do pensamento manifestado, para, em sendo o caso, responder por eventuais danos a terceiros" (SILVA, 2017, p.247), permitindo o exercício do direito de resposta, também previsto na Constituição, proporcional ao agravo e sem prejuízo de indenizações.

Por sua vez, a liberdade de informação "compreende a procura, o acesso, o recebimento e difusão de informações ou ideias, por qualquer meio, e sem dependência de censura, respondendo cada qual pelo dano que cometer" (SILVA, 2017, p.248). Essa liberdade engloba tanto a liberdade de informar - corolário da liberdade de pensamento quanto a liberdade de ser informado, que consubstancia "o interesse sempre crescente da coletividade para que tanto os indivíduos como a comunidade estejam informados para o exercício consciente das liberdades públicas" (SILVA, 2017, p.247).

Ao centro da liberdade de informação encontra-se a liberdade de informação jornalística, enquanto canal de realização tanto do direito de informar quanto do direito de ser informado.

Segundo José Afonso da Silva, a liberdade de informar apenas existe e se justifica para a realização do direito dos indivíduos, ou seja, do direito coletivo à informação, mas uma informação que seja correta e imparcial. Deste modo, "a liberdade dominante é a de ser informado, a de ter acesso às fontes de informação, a de obtê-la [...] o deve de informar à coletividade de tais acontecimentos e ideias, objetivamente, sem alterar-lhes a verdade ou esvaziar-lhes o sentido original, do contrário, se terá não informação, mas deformação" (SILVA, 2017, p.249).

Em outras palavras, pode-se afirmar, sem nenhuma dúvida, que a liberdade de informar - e tão logo de expressar o pensamento e opinião não é, como qualquer outra liberdade, absoluta, mas cinge-se pelo direito que o indivíduo e a coletividade possuem de serem informados de forma imparcial e objetiva, ou seja, o direito a uma informação que - para não usar o termo 'verdadeira' - que verificável, confiável.

De fato, englobada na liberdade de expressão, a liberdade de informar não pode ser censura, uma vez que

Não é o Estado que deve estabelecer quais as opiniões que merecem ser tidas como válidas e aceitáveis; essa tarefa cabe, antes, ao público a que 
essas manifestações se dirigem [...] Estamos, portanto, diante de um direito de índole marcadamente defensiva - direito a uma abstenção pelo Estado de uma conduta que interfira sobre a esfera de liberdade do indivíduo" (BRANCO, 2018, p.269).

Porém, a criação e a propagação de uma notícia que não pode ser verificada e tão logo não pode ser confiável é uma violação da própria liberdade de informação, causando um dano que é não apenas individual, mas coletivo, uma vez que a informação é imperativa para a formação da opinião pública que guia o exercício das liberdades públicas. Do mesmo modo é importante notar que a doutrina lida com a liberdade de comunicação ainda de modo clássico, ou seja, embebida do espírito das revoluções liberais que entende a liberdade de comunicação como uma defesa contra a arbitrariedade do Estado. Em tempos de notícias falsas, 'fake news', a violação da liberdade de comunicação não é perpetrada pelo Estado, por meio da censura, mas sua violação é realizada por agentes privados por meio do abuso desta liberdade.

Branco (2018) endossa a mesma percepção quando recorda que a verdade deve ser o limite primordial para a liberdade de expressão. Isso não significa um embaraço para o exercício da atividade jornalística, mas um dever de cautela imposto àquele que dela se serve de que as informações que veicula - aptas a formar opinião e, tão logo, conduzir a percepção de multidões sobre o estado das coisas - seja precedida de um processo de apuração, certificando-se não da verificabilidade das informações divulgadas.

\section{O TRIBUNAL SUPERIOR ELEITORAL NAS ELEIÇÕES DE 2018: LIBERDADE DE EXPRESSÃO x DESINFORMAÇÃO}

A atuação do Tribunal Superior Eleitoral no combate as fake news, foi iniciada com antecedência ao período eleitoral em si. Em dezembro de 2017, o Tribunal realizou o Seminário "Internet e Democracia”, em que reuniu especialistas e atores sociais para realizar a discussão sobre notícias falsas. 
Em seguida, o Tribunal criou por meio da Portaria TSE 949, de 07 de dezembro de 2017, o Conselho Consultivo sobre Internet e Eleições (CCITE), formado por 14 integrantes não remunerados, entre representantes da Justiça Eleitoral, do Ministério Público, do Ministério da Defesa, do Ministério da Justiça, do Departamento de Polícia Federal, do Ministério da Ciência e Tecnologia, entre outros órgãos públicos, e da sociedade civil. Rais (2018) aponta que o CCITE ficou inerte por quatro meses antes das eleições.

0 tribunal realizou ainda campanhas internas e externas de divulgação de informação verdadeira, manteve o site "Esclarecimentos sobre informações falsas" e atuou em parceria com as agências de checagem de fatos e verificação de informação, tais como Projeto Comprova, "Fato ou Fake", "Aos Fatos", Agência Lupa e Sala de Democracia Digital da Fundação Getúlio Vargas. Todas essas medidas são indicadas como positivas no Relatório Preliminar da Missão de Observação Eleitoral da Organização dos Estados Americanos realizada no Brasil.

Outra ação realizada foi a assinatura de termos de compromisso com partidos políticos, com Clube Associativo dos Profissionais de Marketing Político (Camp), e memorandos entendimento com entidades representativas do setor de comunicação e com as empresas Google e Facebook para manutenção de um ambiente eleitoral imune de disseminação de notícias falsas (TRIBUNAL SUPERIOR ELEITORAL, 2018)

Apesar disso, Ruediger (2018) entende que a atuação do TSE foi aquém do necessário, dada a profusão de fake news e robôs. Entende que muito foi deixado a cargo de plataformas como Facebook e Twitter, mas não houve uma boa articulação com elas, além de não ter havido nenhuma articulação com o Whatsapp. Além disso, sendo uma eleição financiada basicamente por recursos públicos, poderiam ter havido auditorias mais profundas para compreender quem produzia a informação para os candidatos, como exemplo a obrigatoriedade de as campanhas abrirem sua Interface de Programação de Aplicativos

Cumpre destacar que no âmbito da legislação brasileira, foi criado um marco legal seguro de proteção às notícias falsas, considerando toda a problemática exposta acima. A proteção da privacidade e dos dados pessoais são dois dos princípios que disciplinam o uso da internet, 
conforme o art. 3ำ Lei 12.965/2014 (Marco Civil da Internet). Temos também a Lei 13.709, de 14 de agosto de 2018, que dispõe sobre a proteção de dados e altera o Marco Civil da Internet. A Lei 9504/07, art. 57-E (Lei das Eleições), com alteração realizada em 2009 já proibia a venda de cadastros de eletrônicos (art. 57-E da Lei das Eleições).

A Resolução no 23.551, de 18 de dezembro de 2017 estabeleceu que a livre manifestação do pensamento do eleitor seria passível de limitação quando ocorrer ofensa à honra de terceiros ou divulgação de fatos sabidamente inverídicos ${ }^{22}$. Com base no art. 222 do Código eleitoral $^{23}$, o Min. Luiz Fux, quando ocupava a presidência do TSE, chegou a declarar que as eleições poderiam ser anuladas, caso comprovado o vício da votação por causa da disseminação de notícias falsas (RAMALHO, 2018), posição que não foi ratifica por outros ministros ou mesmo pela posição do Tribunal.

Conforme balanço divulgado pelo Tribunal, foram protocoladas 50 ações sobre notícias falsas, o que representou menos de $12 \%$ do total das demandas submetidas aos três ministros designados para atuar no julgamento desses tipos de processos. Dentre eles, 48 foram respondidas prontamente e tiveram decisão sobre o pedido liminar em menos de dois dias e 16 tiveram êxito parcial ou total, com o deferimento dos pedidos de tutela de urgência (TRIBUNAL SUPERIOR ELEITORAL, 2018).

Ficou evidenciado, no geral, que o tribunal privilegiou a proteção à liberdade de expressão, tendendo a reprimir decisões de conteúdo manifestamente inverídico e não apenas crítico, ainda que não baseado em certeza da veracidade.

Foi o que aconteceu, por exemplo, no caso de representação pelo PDT que pedia a remoção de matéria do Portal UOL, exclusão de vídeos do youtube e textos divulgados em outros portais sobre que relacionavam o então candidato Ciro Gomes a codinomes mencionados em planilhas da Construtora Odebrecht, relativos a eventuais pagamentos de propinas a políticos. A min. Rosa Weber considerou que as notícias tratavam de informações prejudiciais que tanto poderiam ser verdadeiras ou não. ${ }^{24}$

Diferentemente, decidiu representação realizada pela $\operatorname{REDE}^{25}$ contra um perfil anônimo no Facebook denominado "ANTI-PT", com várias postagens de notícias afirmavam que a candidata Marina Silva 
havia recebido propina. Uma das notícias afirmava que uma executiva da Odebrecht havia confirmado que a candidata recebera o valor de 1,25 milhões de reais. Nesse caso, o Ministro Sérgio Banhos entendeu que a liberdade de expressão não incluía o anonimato, e que a ausência de identificação de autoria das notícias indicava a necessidade de remoção das publicações do perfil público. Definiu ainda que as informações não tinham comprovação e que afirmavam fatos desprovidos de fonte ou referência, com objetivo de criar comoção a respeito da pré-candidata.

De acordo com o Relatório Preliminar da Missão de Observação Eleitoral da Organização dos Estados Americanos nas eleições brasileiras em $2018^{26}$, um dos os desafios mais complexos do processo eleitoral brasileiro, foi a desinformação propagada por redes sociais e serviços de mensagens na internet. Apesar da disseminação de notícias falsas já ter sido percebido nas eleições em outros países, a dificuldade aqui apresentada se deu pelo uso do sistema criptografado de mensagens para a desinformação massiva.

Quanto a esse ponto, Rais (2018) afirma que nas eleições mexicanas o aplicativo whatsapp também foi um ator importante e que isso não era desconhecido pela Justiça Eleitoral, sendo um grande entrave o fato de ser uma plataforma de comunicação privada, sendo a principal falha não a falta de remoção de conteúdo, mas a falta de investigação da fábrica das notícias fraudulenta.

\section{CONSIDERAÇõES FINAIS}

A divulgação de notícias fraudulentas no século XXI está situada num contexto complexo que alia aspectos tecnológicos a processos políticos em que cada vez mais se fragmenta a construção política e a esfera pública. A desinformação é um processo complexo que envolve riscos concretos à democracia, bem como viola pressupostos básicos da noção de liberdade de expressão e comunicação e direito à informação, constituídas tanto a nível constitucional, quanto internacional.

Para combater esses riscos, é necessário adotar terminologia adequada, a fim de situar o problema que se quer combater e prevenir 
limitantes oportunistas e autoritárias por parte do Estado à liberdade de expressão, como já tem ocorrido.

Para reconstituir a credibilidade na informação, do ponto de vista jornalístico, não há saída, se não uma boa prática jornalística. O Instituto Reuters para o Estudo do Jornalismo, da Universidade de Oxford (Inglaterra), fez levantamento com 143 editores e executivos de veículos de comunicação de 24 países, inclusive o Brasil, entre os quais $70 \%$ afirmaram que a preocupação generalizada com notícias falsas fortalecerá o jornalismo em 2017 (SÁ, 2017).

A pluralidade de fontes e desconcentração dos meios de comunicação, a possibilidade de reconstrução da notícia por uma boa apuração, a autocrítica necessária ao jornalismo que tem seguido o "modelo redes sociais" de produzir notícias (rasas, com fatos irrelevantes, com manchetes sensacionalistas em busca de "cliques"), são todos elementos importantes para ampliação e reconstituição da confiança.

A partir do que vem ocorrendo no cenário internacional, pode-se perceber que o uso das notícias fraudulentas e desinformação nas eleições presidenciais de 2018, que não sabemos até que ponto foi decisivo para o resultado, mas certamente pautou a campanha do presidente eleito, não chegam a um termo final com o processo eleitoral. A atuação do Tribunal Superior Eleitoral, apesar da celeridade, demonstrou-se insuficiente para enfrentar a desinformação.

Cada vez mais será exigido um esforço transdisciplinar para garantia e construção dos pilares da democracia na era digital, dentre os quais a confiança e a informação, são pressupostos básicos. 


\section{NOTAS}

1 Papa Francisco apoiou Donald Trump, o ex-presidente norte-americano Barak Obama fundou o Estado Islâmico; a ex-primeira dama, Michele Obama, é um homem, Barack Obama não é norte-americano, a permanência da Grã-Bretanha na União Europa custa 350 milhões de libras por semana aos cofres públicos, e esse recurso seria destinado ao serviço público de saúde com a saída do bloco. Todos são exemplos de notícias falsas que pautaram os respectivos acontecimentos políticos que trouxeram a temática para o debate público.

2 Claire Wardle, é PhD e diretora executiva do projeto First Draft, vinculado a Shorenstein Center on Media, Politics and Public Policy at the Harvard Kennedy School. Hossein Derakhshan é escritor e pesquisador. Ambos são autores do Relatório INFORMATION DISORDER : Toward and interdisciplinary framework for research and policy making, encomendado pelo Conselho da Europa, publicado em 2017. 0 projeto First Draft tem como objetivo encontrar soluções aos desafios associados a confiança e verdade na era digital. Disponível em https://firstdraftnews. org/wp-content/uploads/2017/10/Information_Disorder_FirstDraft-CoE_2018.pdf?x40896 Acesso em 15 nov 2018.

3 De acordo com os autores, o discurso de ódio, assédio e vazamentos levantam inúmeras questões distintas, mas não puderam ser considerados no relatório. (p.22)

4 Ficou conhecida a atuação de jovens macedônios na criação de notícias fraudulentas, a maioria pró-Trump, nas eleições norte-americanas. A motivação deles não era política, mas sobretudo financeira, tendo em vista que o Facebook paga 4 vezes mais por leitor norte-americano (SÁ, 2017). 0 fato também é retratado no documentário "Fake News - Baseado em fatos reais" produzido pela Globonews, em que um jovem afirma que direcionou as notícias para o eleitorado de Trump por que elas faziam mais sucesso nesse público, ao contrário do que acontecia com os eleitores de Hillary Clinton, que não acreditavam em "qualquer coisa".

5 "CA political has been provided the stronger relationship between data and marketing. Basically, it combines the predictive data analytics, behavioural sciences, and innovative ad tech into one award winning approach. With the use of CA political, you can engage the customers more effectively and efficiently." Tradução Livre. Disponível em https://ca-political.com/?_hstc=163013475. 7f6ca08d75c87e769c091acb206e6b4b.1541292537069.1541292537069.1542586415298.2\& hssc=163013475.1.1542586415298\&_hsfp=1242282205, Acesso em 18 nov 2018.

6 Baseado em 10 curtidas, o computador pôde prever melhor a personalidade do que um colega de trabalho; com 70 "curtidas", foi melhor do que um amigo ou colega de quarto; com 150 curtidas, melhor do que um pai ou irmão; e depois de 300 curtidas, melhor do que um cônjuge

7 9. Que a liberdade de expressão, e debates ou procedimentos no Parlamento, não devem ser impedidos ou questionados por qualquer tribunal ou local fora do Parlamento.

8 XII. Que a liberdade de imprensa é um dos grandes baluartes da liberdade, não podendo ser restringida jamais, a não ser por governos despóticos.

9 Art. $10^{\circ}$. Ninguém pode ser molestado por suas opiniões, incluindo opiniões religiosas, desde que sua manifestação não perturbe a ordem pública estabelecida pela lei.

10 "Todo ser humano tem direito à liberdade de opinião e expressão; esse direito inclui a liberdade de, sem interferência, ter opiniões e de procurar, receber e transmitir informações e ideias por quaisquer meios e independentemente de fronteiras".

11 ARTIGO 19. 1. Ninguém poderá ser molestado por suas opiniões. 2. Toda pessoa terá direito à liberdade de expressão; esse direito incluirá a liberdade de procurar, receber e difundir informações e ideias de qualquer natureza, independentemente de considerações de fronteiras, verbalmente ou por escrito, em forma impressa ou artística, ou por qualquer outro meio de sua escolha. 3. 0 exercício do direito previsto no parágrafo 2 do presente artigo implicará deveres e responsabilidades especiais. Consequentemente, poderá estar sujeito a certas restrições, que devem, entretanto, ser expressamente previstas em lei e que se façam necessárias para: a) assegurar o respeito dos direitos e da reputação das demais pessoas; b) proteger a segurança nacional, a ordem, a saúde ou a moral públicas.

12 ARTIGO $10^{\circ}$. Liberdade de expressão. 1. Qualquer pessoa tem direito à liberdade de expressão. 
13 Este direito compreende a liberdade de opinião e a liberdade de receber ou de transmitir informações ou ideias sem que possa haver ingerência de quaisquer autoridades públicas e sem considerações de fronteiras. 0 presente artigo não impede que os Estados submetam as empresas de radiodifusão, de cinematografia ou de televisão a um regime de autorização prévia. 2.0 exercício desta liberdades, porquanto implica deveres e responsabilidades, pode ser submetido a certas formalidades, condições, restrições ou sanções, previstas pela lei, que constituam providências necessárias, numa sociedade democrática, para a segurança nacional, a integridade territorial ou a segurança pública, a defesa da ordem e a prevenção do crime, a proteção da saúde ou da moral, a proteção da honra ou dos direitos de outrem, para impedir a divulgação de informações confidenciais, ou para garantir a autoridade e a imparcialidade do poder judicial.

14 ARTIGO 13. 1. Toda pessoa tem direito à liberdade de pensamento e de expressão. Esse direito compreende a liberdade de buscar, receber e difundir informações e ideias de toda natureza, sem consideração de fronteiras, verbalmente ou por escrito, ou em forma impressa ou artística, ou por qualquer outro processo de sua escolha. 2.0 exercício do direito previsto no inciso precedente não pode estar sujeito a censura prévia, mas a responsabilidades ulteriores, que devem ser expressamente fixadas pela lei e ser necessárias para assegurar: a. o respeito aos direitos ou à reputação das demais pessoas; ou b. a proteção da segurança nacional, da ordem pública, ou da saúde ou da moral públicas. 3.Não se pode restringir o direito de expressão por vias ou meios indiretos, tais como o abuso de controles oficiais ou particulares de papel de imprensa, de frequências radioelétricas ou de equipamentos e aparelhos usados na difusão de informação, nem por quaisquer outros meios destinados a obstar a comunicação e a circulação de ideias e opiniões. 4 A lei pode submeter os espetáculos públicos a censura prévia, com o objetivo exclusivo de regular o acesso a eles, para proteção moral da infância e da adolescência, sem prejuízo do disposto no inciso 2 . 5. A lei deve proibir toda propaganda a favor da guerra, bem como toda apologia ao ódio nacional, racial ou religioso que constitua incitação à discriminação, à hostilidade, ao crime ou à violência.

15 IV - é livre a manifestação do pensamento, sendo vedado o anonimato;

$16 \mathrm{~V}$ - é assegurado o direito de resposta, proporcional ao agravo, além da indenização por dano material, moral ou à imagem;

17 IX - é livre a expressão da atividade intelectual, artística, científica e de comunicação, independentemente de censura ou licença;

18 XII - é inviolável o sigilo da correspondência e das comunicações telegráficas, de dados e das comunicações telefônicas, salvo, no último caso, por ordem judicial, nas hipóteses e na forma que a lei estabelecer para fins de investigação criminal ou instrução processual penal;

19 XIV - é assegurado a todos o acesso à informação e resguardado o sigilo da fonte, quando necessário ao exercício profissional;

20 Art. 220. A manifestação do pensamento, a criação, a expressão e a informação, sob qualquer forma, processo ou veículo não sofrerão qualquer restrição, observado o disposto nesta Constituição.

$21 \S 1$ o Nenhuma lei conterá dispositivo que possa constituir embaraço à plena liberdade de informação jornalística em qualquer veículo de comunicação social, observado o disposto no art. 5o, IV, V, X, XIII e XIV.

$22 \S 2^{\circ}$ É vedada toda e qualquer censura de natureza política, ideológica e artística.

"Art. 22. É permitida a propaganda eleitoral na internet a partir do dia 16 de agosto do ano da eleição (Lei no 9.504/1997, art. 57-A). § 1ํA A livre manifestação do pensamento do eleitor identificado ou identificável na internet somente é passível de limitação quando ocorrer ofensa à honra de terceiros ou divulgação de fatos sabidamente inverídicos".

23 Art. 222. É também anulável a votação, quando viciada de falsidade, fraude, coação, uso de meios de que trata o Art. 237, ou emprego de processo de propaganda ou captação de sufrágios vedado por lei.

24 RP 0600720-79

25 REPRESENTAÇ̃̃O № 060054670.2018.6.00.0000

26 A missão foi liderada pela ex-presidente da Costa Rica Laura Chinchila, integrada por 30 especialistas e observadores de 17 nacionalidades e 6 pessoas que observaram o voto no exterior. Interessante destacar que a própria missão foi objeto de desinformação, com a divulgação de imagens em que sua líder aparecia ao lado dos ex-presidentes Luis Inácio Lula da Silva e Hugo Chavez, com a mensagem "ESSA É A MOÇA QUE VEIO FISCALIZAR AS URNAS ELETRÔNICAS NO BRASIL!!! ESPALHEM!". 


\section{REFERÊNCIAS}

BARENDT, Eric et al. Media Law: Text, Cases and Materials. Harlow: Pearson, 2014.

BRANCO, Paulo Gustavo Gonet. Liberdades. In: MENDES, Gilmar Ferreira; BRANCO, Paulo Gustavo Gonet. Curso de Direito Constitucional. 7 ed. São Paulo: Saraiva, IDP, 2012.

BRANCOa, Sérgio, Fake News e o caminho para fora da bolha. Interesse Nacional. Ago-Out. 2017. Disponível em: https://itsrio.org/wp-content/ uploads/2017/08/sergio-fakenews.pdf. Acesso em 05 nov. 2018

BUCCI, Eugenio. Jornal O Povo, 07 jan, 2018, [Entrevista] Disponível em https:// www.opovo.com.br/jornal/dom/2018/01/confira-integra-da-entrevista-comeugenio-bucci.html

CELLAN-JONES, Rory. Fake news worries 'are growing' suggests BBC poll. BBC News. 22 set. 2017. Disponível em: https://www.bbc.com/news/ technology-41319683. Acesso em 14 nov. 2017.

CLETO, Murilo. O triunfo da antipolítica In: JINKINGS, Ivana et.al Porque Gritamos Golpe? São Paulo: Boitempo, 2016

COMO TRUMP E O BREXIT AJUDARAM A CUNHAR A 'PALAVRA DO ANO' ESCOLHIDA PELO DICIONÁRIO OXFORD. BBC Brasil, 16 nov 2016, Disponível em https://www.bbc.com/portuguese/internacional-37998165. Acesso em 16 nov. 2018.

CORSALETTE, Conrado. Pós-verdade, fake news e as eleições no Brasil. Nexo Jornal, 27 mai 2018. (PodCast) Disponível em https://www.nexojornal. com.br/podcast/2 018/05/27 /P\%C3\%B3s-verdade-fake-news-e-aselei\%C3\%A7\%C3\%B5es-no-Brasil. Acesso em 04 nov 2018.

ELEIÇÕES 2018: ACORDO PARA NÃO PROLIFERAÇÃO DE NOTÍCIAS FALSAS CONTA COM ASSINATURA DE 28 PARTIDOS. Tribunal Superior Eleitoral. Brasília, 09 jul. 2018. Disponível em: http://www.tse.jus.br/imprensa/noticiastse/2018/Julho/eleicoes-2018-acordo-para-nao-proliferacao-de-noticias-falsasconta-com-assinatura-de-28-partidos. Acesso em: 23 nov. 2018. 
ERLANGER, STEVEN. Los políticos adoptan la excusa de 'noticias falsas' de Trump. The New York Times, 14 dez 2017. Disponível em https://www.nytimes. com/es/2017/12/14/excusa-noticias-falsas-trump-china-filipinas-putin/. Acesso em 05 nov 2018.

FACEBOOK 'LIKES' REVEAL YOUR TRUE PERSONALITY. DailyMail. 13 jan. 2015. Disponível em https://www.dailymail.co.uk/wires/afp/article-2907329/ Facebook-likes-reveal-true-personality.html

HANCOCK, Jaime Rubio. Dicionário Oxford dedica sua palavra do ano, pósverdade a Trump e Brexit. El País. Central European Time, 17 nov. 2016. Disponível em:

MARTINS, Helena. Era dos Robôs chega às eleições. Agência Brasil. Brasília, 21 dez. de 2017. Disponível em: http://agenciabrasil.ebc.com.br/geral/ noticia/2017-12/fake-news-censura-e-controle-na-internet-era-dos-roboschega-eleicoes. Acesso em 10 nov 2018.

Tecnologia muda estratégia de comunicação em campanhas eleitorais. Agência Brasil. Brasília, 21 de dez 2017. Disponível em http:// agenciabrasil.ebc.com.br/geral/noticia/2017-12/tecnologia-muda-estrategiade-comunicacao-em-campanhas-eleitorais. Acesso em 10 nov. 2018

MOZILLA. Internet Health Report. V_01., jan. 2017. Disponível em: https:// d20x8vt12bnfa2.cloudfront.net/InternetHealthReport_v01.pdf. Acesso em 14 nov. 2018.

ORGANIZAÇÃO DOS ESTADOS AMERICANOS, Relatório Preliminar MOE. Disponível em: http://www.oas.org/documents/por/press/RelatorioPreliminar-MOE-Brasil-2o-Turno-Portugues.pdf. Acesso em 10 nov. 2018

RAIS, Diego. 0 que o TSE fez e não fez no combate as notícias falsas. Nexo Jornal. 15 out. 2018. [Entrevista concedida a Lilian Venturini] https://www.nexojornal. com.br/expresso/2018/10/15/0-que-o-TSE-fez-e-o-que-n\%C3\%A3o-fez-nocombate-a-not\%C3\%ADcias-falsas

RAMALHO, Renan. Fux diz que a Justiça pode anular uma eleição se resultado for influenciado por fake news em massa. Portal G1. Brasília, 21 jun. 2018. Disponível em: https://g1.globo.com/politica/eleicoes/2018/noticia/fux-diz- 
que-justica-pode-anular-eleicao-se-resultado-for-fruto-de-fake-news-em-massa. ghtml. Acesso em: 22 nov.2018

RUEDIGER, MARCO AURELIO. O que o TSE fez e não fez no combate as notícias falsas. Nexo Jornal. 15 out. 2018. [Entrevista concedida a Lilian Venturini] https://www.nexojornal.com.br/expresso/2018/10/15/0-que-o-TSE-fez-e-oque-n\%C3\%A3o-fez-no-combate-a-not\%C3\%ADcias-falsas

SÁ, Nelson de. Como os grandes jornais e as mídias sociais tentam responder a invenção deliberada de fatos. Folha de São Paulo, 19 fev 2017. Disponível em https://www1.folha.uol.com.br/ilustrissima/2017/02/1859992-como-osgrandes-jornais-e-as-midias-sociais-tentam-responder-a-invencao-deliberadade-fatos.shtml. Acesso em 05 nov. 2018.

SILVA, José Afonso da. Curso de Direito Constitucional Positivo. 40.ed.rev. atual. São Paulo: Malheiros, 2017.

SUMARES, Gustavo. 55\% dos brasileiros acham que o facebook é a internet, diz pesquisa. Olhar Digital. 19 jan 2017, Disponível em: https://olhardigital. com.br/noticia/55-dos-brasileiros-acham-que-o-facebook-e-a-internet-dizpesquisa/65422. Acesso em: 14 nov 2018

TRIBUNAL SUPERIOR ELEITORAL, Portaria no 949, de 7 de dezembro de 2017. Institui o Conselho Consultivo sobre Internet e Eleições.http://www.tse. jus.br/legislacao-tse/prt/2017/PRT09492017.html. Acesso em: 22 nov. 2018.

TSE atuou com celeridade no julgamento de processos sobre fake news durante as Eleições 2018. Tribunal Superior Eleitoral. Brasília, 16 nov. 2018. http://www. tse.jus.br/imprensa/noticias-tse/2018/Novembro/tse-atuou-com-celeridadeno-julgamento-de-processos-sobre-fake-news-durante-as-eleicoes-2018

UNITED NATIONS. Joint Declaration on 'Fake News', Disinformation and Propaganda. Disponível em: https://www.ohchr.org/EN/NewsEvents/Pages/ DisplayNews.aspx?NewsID=21287\&LangID=E. Acesso em: 10.nov.2018.

VENTURINI, Lilian. Qual o rumo das decisões do TSE sobre fake News. Nexo Jornal. 21 jul 2018. Disponível em https://www.nexojornal.com.br/ expresso/2018/07/21/Qual-o-rumo-das-decis\%C3\%B5es-do-TSE-sobre-fakenews Acesso em 05 nov 2018. 
WARDLE, Claire, HOSSEIN, Derakhshan. Information Disorder: Toward an interdisciplinary framework for research and policy making. Concil of Europe: Strasbourg, 2017.

Recebido em: 24-11-2018

Aprovado em: 18-12-2019

\section{André Soares Oliveira}

Doutor em Direito - Fundamentos da Experiência Jurídica - pela Universidade Federal do Rio Grande do Sul; mestre em Direito - Relações Internacionais pela Universidade Federal de Santa Catarina; professor da Faculdade Paraíso do Ceará; líder do grupo de pesquisa Constitucionalismo Contemporâneo e Democracia CCD/FAPCE, pesquisador dos grupos de pesquisa EMAE/UFSC (Estudos Avançados em Meio Ambiente e Economia no Direito Internacional) e no Propriedade Intelectual, Transferência de Tecnologia e Inovação/UFSC. E-mail: asoliveira3@gmail.com

\section{Patrícia Oliveira Gomes}

Professora de Ciência Política e Teoria Geral do Estado no Curso de Direito da Faculdade Paraíso do Ceará, em Juazeiro do Norte/CE. ; mestre pelo Programa de Pós Graduação da Faculdade de Direito da Universidade Federal do Ceará; advogada. E-mail: patriciaog11@gmail.com 
